Review article

\title{
Vitamin D across growth hormone (GH) disorders: From GH deficiency to GH excess
}

\author{
A. Ciresi, C. Giordano* \\ Section of Endocrinology, Biomedical Department of Internal and Specialist Medicine (DIBIMIS), University of Palermo, Piazza delle Cliniche 2, 90127 Palermo, Italy
}

\section{A R T I C L E I N F O}

\section{Article history:}

Received 4 September 2016

Received in revised form 22 December 2016

Accepted 24 February 2017

Available online 27 February 2017

\section{Keywords:}

Growth hormone

Growth hormone deficiency

Acromegaly

Vitamin D

\begin{abstract}
A B S T R A C T
The interplay between vitamin D and the growth hormone (GH)/insulin-like growth factor (IGF)-I system is very complex and to date it is not fully understood. GH directly regulates renal 1 alpha-hydroxylase activity, although the action of GH in modulating vitamin D metabolism may also be IGF-I mediated. On the other hand, vitamin D increases circulating IGF-I and the vitamin D deficiency should be normalized before measurement of IGF-I concentrations to obtain reliable and unbiased IGF-I values. Indeed, linear growth after treatment of nutritional vitamin D deficiency seems to be mediated through activation of the GH/IGF-I axis and it suggests an important role of vitamin D as a link between the proliferating cartilage cells of the growth plate and GH/IGF-I secretion. Vitamin D levels are commonly lower in patients with GH deficiency (GHD) than in controls, with a variable prevalence of insufficiency or deficiency, and this condition may worsen the already known cardiovascular and metabolic risk of GHD, although this finding is not common to all studies. In addition, data on the impact of GH treatment on vitamin D levels in GHD patients are quite conflicting. Conversely, in active acromegaly, a condition characterized by a chronic GH excess, both increased and decreased vitamin D levels have been highlighted, and the interplay between vitamin D and the GH/IGF-I axis becomes even more complicated when we consider the acromegaly treatment, both medical and surgical.

The current review summarizes the available data on vitamin D in the main disorders of the GH/IGF-I axis, providing an overview of the current state of the art.
\end{abstract}

@ 2017 Elsevier Ltd. All rights reserved.

\section{Introduction}

The relationship between vitamin D and the growth hormone (GH)/ insulin-like growth factor (IGF)-I system is complex and to date it is not univocally clarified. Adequate vitamin D levels are necessary for calcium homeostasis and mineralization of the skeleton and vitamin D deficiency may contribute to low bone mineral density both in children and in adult patients. When vitamin $\mathrm{D}$ concentrations are inadequate, calcium absorption from the gut is also inadequate and its concentrations begin to decrease. As serum calcium levels fall, there is increased activity of parathyroid hormone (PTH), which promotes calcium loss from the bone to counteract the decline in serum calcium concentrations and the clinical features, such as rachitic bone changes, become apparent.

\footnotetext{
Abbreviations: GH, growth hormone; GHT, growth hormone treatment; GHD, growth hormone deficiency.

* Corresponding author at: Section of Cardio-Respiratory and Endocrine-Metabolic Diseases, Biomedical Department of Internal and Specialist Medicine (DIBIMIS), University of Palermo, Piazza delle Cliniche 2, 90127 Palermo, Italy.

E-mail address: carla.giordano@unipa.it (C. Giordano).
}

In $\mathrm{GH}$ disorders, from $\mathrm{GH}$ deficiency (GHD) to GH excess, skeletal disorders are a common condition [1]. However, the role of vitamin D in bone health has not always been evaluated in these conditions. It is well known that GH, either directly or indirectly through IGF-I, stimulates osteoblastogenesis and chondrogenesis. Low bone turnover and decreased bone mineral density are frequently reported in childhoodonset GHD, while in patients with adult-onset GHD the data are discordant [2,3]. On the other hand, markers of bone formation and resorption increase in patients with GH excess [4].

Acromegalic osteopathy is a complication of acromegaly characterized by increase in bone turnover, deterioration in bone architecture and high risk of vertebral fractures. However, the pathogenesis of acromegalic osteopathy is multifactorial and fractures may occur even in the presence of normal bone mineral density [5]. In this context too, the impact of vitamin D concentrations is not fully clarified. In addition, the impact of vitamin $\mathrm{D}$ on metabolic diseases and the relationships of vitamin $\mathrm{D}$ with diabetes, insulin resistance and metabolic syndrome are being increasingly investigated. Given that both GHD and acromegaly are associated with metabolic abnormalities and that both $250 \mathrm{H}-\mathrm{D} 3$ and IGF-I levels are associated with the metabolic syndrome [6], a role of vitamin $\mathrm{D}$ deficiency in these conditions cannot be ruled out. The 
current review summarizes the available data on vitamin $\mathrm{D}$ in the main disorders of the GH/IGF-I axis, with the aim of clarifying the role of vitamin $\mathrm{D}$ in these conditions and providing an overview of the current state of the art.

\section{Selection of studies for review}

PubMed was searched for English-language studies evaluating the vitamin D levels in patients with GHD or acromegaly and/or their changes over time after specific treatment. The search terms used were "growth hormone and vitamin D", "growth hormone deficiency and vitamin D" and "acromegaly and vitamin D". The studies that were included reported vitamin D levels as the primary or secondary objective of the study from 1978 to Jun 2016. From the totality of studies found using the above-mentioned key terms, 18 studies fulfilled our criteria for analysis in GHD patients (Table 1) and 18 studies fulfilled our criteria for analysis in acromegalic patients (Table 2).

\section{Growth hormone/IGF-I axis and vitamin D}

The relationship between vitamin $\mathrm{D}$ metabolism and the GH/IGF axis is shown in the Fig. 1.

\subsection{GH and vitamin D}

In rats it has been demonstrated that $\mathrm{GH}$ can modulate the renal metabolism of 25-hydroxy vitamin D (25OH-D3) and affect intestinal calcium absorption by stimulating the production of 1,25-dihydroxy vitamin $\mathrm{D}$ [1,25(OH)2-D3], the hormonally active vitamin D metabolite [7]. In hypophysectomized rats, the renal conversion of $25 \mathrm{OH}-\mathrm{D} 3$ to $1,25(\mathrm{OH}) 2-$ D3 was markedly reduced compared with sham-operated rats, while the renal conversion of 25OH-D3 to 24,25-dihydroxycholecalciferol [24,25-(OH)2-D3] was markedly increased. Treatment of rats with GH for 10 days resulted in a significant increase in renal conversion of $25 \mathrm{OH}-\mathrm{D} 3$ to $1,25(\mathrm{OH}) 2-\mathrm{D} 3$ and a significant decrease in conversion to 24,25(OH)2-D3 [8,9].

Studies evaluating the role of GH in vitamin D metabolism in healthy subjects support this concept. In 1994 Ogle et al. demonstrated a significant stimulatory effect of GH treatment on 1,25(OH)2-D3 levels in 11 healthy short-statured children [10]. Further, Marcus et al. confirmed this effect in 16 healthy elderly adults. Indeed, while aging is associated with a decline in serum 1,25(OH)2-D3 levels [11], the authors of this study speculated about the role of $\mathrm{GH}$ as a potential agent for attenuating or reversing the loss of muscle and bone in elderly people [12]. Similar stimulatory effects were obtained when GH was administered for a short-time. Brixen et al. showed a significant increase in total vitamin $\mathrm{D}$ in 20 normal male volunteers after just 7 days of treatment with a pharmacological dosage of GH [13], and GH infusions in 7 normal healthy male volunteers increased 1,25(OH)2-D3 levels within $36 \mathrm{~h} \mathrm{[14].}$

\subsection{IGF-I and vitamin D}

The mutual relationship between IGF-I and vitamin D has been well clarified by studies performed in vitro and in vivo, in both children and adults. However, whether GH acts on bone metabolism and vitamin D directly or indirectly via increased IGF-I synthesis remains unclear. It is well demonstrated that IGF-I directly stimulates production of 1,25(OH)2-D3 by kidney cells in vitro, independently of GH [15]. Similarly, in healthy subjects GH seems to affect serum 1,25(OH)2-D3 independently of circulating PTH, and this effect appears to be mediated by IGF-I. Therefore, one potential mechanism by which GH stimulates increases in bone mass is via increases in IGF-I and consequently in

Table 1

Selected studies for analysis on GHD patients.

\begin{tabular}{|c|c|c|c|c|c|c|}
\hline Reference & Diagnosis & $\begin{array}{l}\text { No. of } \\
\text { patients }\end{array}$ & $\begin{array}{l}\text { Parameter } \\
\text { evaluated }\end{array}$ & $\begin{array}{l}\text { Vit D levels at baseline } \\
\text { (compared to controls or to normal values) }\end{array}$ & $\begin{array}{l}\text { Duration of treatment } \\
\text { (months) }\end{array}$ & $\begin{array}{l}\text { Vit D levels after } \\
\text { treatment }\end{array}$ \\
\hline Gertner et al., 1979 & CGHD & 9 & $\begin{array}{l}\text { 25OH-D3 } \\
1,25(\mathrm{OH}) 2-\mathrm{D} 3 \\
24,25(\mathrm{OH}) 2-\mathrm{D} 3\end{array}$ & $\begin{array}{l}- \\
- \\
-\end{array}$ & 12 & $\begin{array}{l}\text { Unchanged } \\
\text { Unchanged } \\
\text { Unchanged }\end{array}$ \\
\hline Chipman et al., 1980 & CGHD & 7 & $1,25(\mathrm{OH}) 2-\mathrm{D} 3$ & - & $5-14$ & Decreased \\
\hline Burstein, 1983 & CGHD & 12 & 1,25(OH)2-D3 & $\begin{array}{l}- \\
- \\
-\end{array}$ & $\begin{array}{l}7 \text { days } \\
1 \\
12\end{array}$ & $\begin{array}{l}\text { Increased } \\
\text { Unchanged } \\
\text { Unchanged }\end{array}$ \\
\hline Binnerts, 1992 & AGHD & 8 & $\begin{array}{l}25 \mathrm{OH}-\mathrm{D} 3 \\
1,25(\mathrm{OH}) 2-\mathrm{D} 3\end{array}$ & - & 6 & $\begin{array}{l}\text { Unchanged } \\
\text { Increased }\end{array}$ \\
\hline Saggese, 1993 & CGHD & 26 & $\begin{array}{l}1,25(\mathrm{OH}) 2-\mathrm{D} 3 \\
25 \mathrm{OH}-\mathrm{D} 3\end{array}$ & $\begin{array}{l}\text { Reduced } \\
\text { Normal }\end{array}$ & 12 & $\begin{array}{l}\text { Increased } \\
\text { Unchanged }\end{array}$ \\
\hline Valk, 1995 & AGHD & 6 & $1,25(\mathrm{OH}) 2-\mathrm{D} 3$ & - & 6 & Unchanged \\
\hline Amato, 1996 & AGHD & 9 & 25OH-D3 & Similar & 12 & Unchanged \\
\hline Hansen, 1996 & AGHD & 29 & 1,25(OH)2-D3 & - & 12 & Unchanged \\
\hline Wei, 1997 & CGHD & 12 & $\begin{array}{l}1,25(\mathrm{OH}) 2-\mathrm{D} 3 \\
24,25(\mathrm{OH}) 2-\mathrm{D} 3 \\
25 \mathrm{OH}-\mathrm{D} 3\end{array}$ & Similar & 6 & $\begin{array}{l}\text { Increased } \\
\text { Reduced/unchanged } \\
\text { Unchanged }\end{array}$ \\
\hline Boot, 1997 & CGHD & 39 & $1,25(\mathrm{OH}) 2-\mathrm{D} 3$ & Similar & 36 & Increased \\
\hline Bianda, 1998 & AGHD & 8 & 1,25(OH)2-D3 & $\begin{array}{l}- \\
-\end{array}$ & $\begin{array}{l}3 \text { days (GHT) } \\
5 \text { days (IGF-I T) }\end{array}$ & $\begin{array}{l}\text { Increased } \\
\text { Increased }\end{array}$ \\
\hline de Boer, 1998 & AGHD & 50 & $1,25(\mathrm{OH}) 2-\mathrm{D} 3$ & Similar & - & - \\
\hline Ahmad, 2003 & AGHD & 16 & $\begin{array}{l}25 \mathrm{OH}-\mathrm{D} 3 \\
1,25(\mathrm{OH}) 2-\mathrm{D} 3\end{array}$ & - & 12 & $\begin{array}{l}\text { Increased } \\
\text { Increased }\end{array}$ \\
\hline Hitz, 2006 & AGHD & 34 & $\begin{array}{l}\text { 1,25(OH)2-D3 } \\
\text { 25OH-D3 }\end{array}$ & $\begin{array}{l}\text { Similar in men } \\
\text { Reduced in women } \\
\text { Similar }\end{array}$ & - & $\begin{array}{l}- \\
-\end{array}$ \\
\hline Ciresi, 2014 & CGHD & 80 & 25OH-D3 & $\begin{array}{l}\text { Reduced: } \\
\text { Deficiency (40\%) } \\
\text { Insufficiency (35\%) }\end{array}$ & 12 & Increased \\
\hline Savanelli, 2016 & AGHD & 41 & 25OH-D3 & $\begin{array}{l}\text { Reduced: } \\
\text { Deficiency (51\%) } \\
\text { Insufficiency (26.8\%) }\end{array}$ & - & - \\
\hline Witkowska-Sędek 2016 & CGHD & 84 & $25 \mathrm{OH}-\mathrm{D} 3$ & Reduced & - & - \\
\hline
\end{tabular}

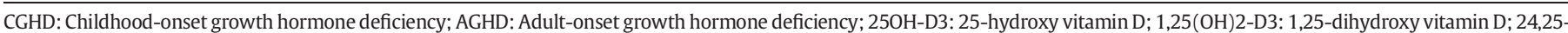
(OH)2-D3: 24,25-dihydroxy vitamin D; SA: somatostatin analogs; GHT: GH treatment; IGF-I T: IGF-I treatment. 
Table 2

Selected studies for analysis on acromegalic patients.

\begin{tabular}{|c|c|c|c|c|c|c|}
\hline Reference & $\begin{array}{l}\text { No. of } \\
\text { patients }\end{array}$ & $\begin{array}{l}\text { Parameter } \\
\text { evaluated }\end{array}$ & $\begin{array}{l}\text { Vit D levels at baseline } \\
\text { (compared to controls or to normal values) }\end{array}$ & Treatment & $\begin{array}{l}\text { Duration of treatment } \\
\text { (months) }\end{array}$ & $\begin{array}{l}\text { Vit D levels after } \\
\text { treatment }\end{array}$ \\
\hline \multirow[t]{3}{*}{ Eskildsen., 1979} & \multirow[t]{3}{*}{15} & 1,25(OH)2-D3 & Increased & \multirow{3}{*}{ Bromocriptine } & \multirow[t]{3}{*}{6} & Reduced \\
\hline & & $24,25(\mathrm{OH}) 2-\mathrm{D} 3$ & Increased & & & Reduced \\
\hline & & $25 \mathrm{OH}-\mathrm{D} 3$ & reduced & & & unchanged \\
\hline Brown, 1980 & 14 & $1,25(\mathrm{OH}) 2-\mathrm{D} 3$ & Increased & - & - & - \\
\hline \multirow[t]{2}{*}{ Но, 1992} & \multirow[t]{2}{*}{25} & \multirow[t]{2}{*}{$1,25(\mathrm{OH}) 2-\mathrm{D} 3$} & \multirow[t]{2}{*}{ Normal } & $\mathrm{SA}(5 \mathrm{pt})$ & 6 & Unchanged \\
\hline & & & & Surgery (2 pt) & - & Unchanged \\
\hline Fiebrich, 2010 & 19 & 25OH-D3 & - & SA & 18 & Reduced \\
\hline \multirow[t]{2}{*}{ Shah, 2012} & \multirow[t]{2}{*}{2} & \multirow[t]{2}{*}{$1,25(\mathrm{OH}) 2-\mathrm{D} 3$} & \multirow[t]{2}{*}{ Increased } & Surgery (1 pt) & - & Reduced \\
\hline & & & & Incomplete surgery ( $1 \mathrm{pt})$ & - & Unchanged \\
\hline \multirow[t]{2}{*}{ Takamoto., 1985} & \multirow[t]{2}{*}{12} & 25OH-D3 & Reduced & \multirow[t]{2}{*}{ Surgery } & \multirow[t]{2}{*}{-} & Unchanged \\
\hline & & $1,25(\mathrm{OH}) 2-\mathrm{D} 3$ & Increased & & & Reduced \\
\hline \multirow[t]{2}{*}{ Parkinson, 2003} & \multirow[t]{2}{*}{16} & $25 \mathrm{OH}-\mathrm{D} 3$ & - & \multirow[t]{2}{*}{ Pegvisomant } & - & Unchanged \\
\hline & & $1,25(\mathrm{OH}) 2-\mathrm{D} 3$ & - & & - & Reduced \\
\hline White, 2006 & 10 & $1,25(\mathrm{OH}) 2-\mathrm{D} 3$ & Increased & Surgery & - & Reduced \\
\hline \multirow[t]{2}{*}{ Lund, 1981} & \multirow[t]{2}{*}{14} & $1,25(\mathrm{OH}) 2-\mathrm{D} 3$ & Increased & \multirow[t]{2}{*}{ Bromocriptine } & \multirow[t]{2}{*}{6} & Reduced \\
\hline & & $24,25(\mathrm{OH}) 2-\mathrm{D} 3$ & Increased & & & Reduced \\
\hline \multirow[t]{4}{*}{ Fredstorp, 1993} & \multirow[t]{4}{*}{16} & $1,25(\mathrm{OH}) 2-\mathrm{D} 3$ & - & \multirow[t]{4}{*}{ Octreotide } & 8-14 days & Increased \\
\hline & & & & & 32 months & Unchanged \\
\hline & & Vitamin D-binding protein & - & & 8-14 days & Unchanged \\
\hline & & & & & 32 months & Unchanged \\
\hline \multirow[t]{2}{*}{ Cappelli, 2004} & 35 & 25OH-D3 & Normal & Lanreotide & 24 & Unchanged \\
\hline & & $1,25(\mathrm{OH}) 2-\mathrm{D} 3$ & Normal & & & Unchanged \\
\hline Bijlsma, 1983 & 17 & 1,25(OH)2-D3 & - & Bromocriptine (12 pt) & - & Decreased \\
\hline & & $24,25(\mathrm{OH}) 2-\mathrm{D} 3$ & - & or & - & Increased \\
\hline & & & & Surgery (5 pt) & & \\
\hline Ho, 1992 & 25 & $1,25(\mathrm{OH}) 2-\mathrm{D} 3$ & Normal & $\mathrm{SA}(5 \mathrm{pt})$ & 6 & Unchanged \\
\hline & & & & Surgery (2 pt) & & Unchanged \\
\hline Lombardi, 2013 & 9 & 25OH-D3 & reduced & SA & 6 & Unchanged \\
\hline Ajmal, 2014 & 125 & $25 \mathrm{OH}-\mathrm{D} 3$ & Normal & SA & 3 & Unchanged \\
\hline & & & & & 76 & Unchanged \\
\hline Halupczok-Żyła., 2015 & 55 & 25OH-D3 & Reduced & - & - & - \\
\hline Altinova, 2016 & & total $25 \mathrm{OH}-\mathrm{D} 3$ & Normal & & & \\
\hline & & Vitamin D binding protein & Increased & - & - & - \\
\hline & & free $250 \mathrm{H}-\mathrm{D} 3$ & Reduced & & & \\
\hline Kamenicky, 2012 & 16 & $25 \mathrm{OH}-\mathrm{D} 3$ & - & & 6 & Unchanged \\
\hline & & $1,25(\mathrm{OH}) 2-\mathrm{D} 3$ & - & - & & Decreased \\
\hline Bonadonna, 2005 & 36 & 25OH-D3 & Reduced & - & - & - \\
\hline
\end{tabular}

25OH-D3: 25-hydroxy vitamin D; 1,25(OH)2-D3: 1,25-dihydroxy vitamin D; 24,25-(OH)2-D3: 24,25-dihydroxy vitamin D; SA: somatostatin analogs.

serum 1,25(OH)2-D3 [16]. Gòmez et al. confirmed these data, showing that IGF-I regulates $250 \mathrm{H}-\mathrm{D} 3$ concentration in 253 healthy adult males [17]. Indeed, it is widely demonstrated that IGF-I causes an increase in the circulating levels of $1,25(\mathrm{OH}) 2-\mathrm{D} 3$ by directly stimulating expression and activity of the $1 \alpha$-hydoxylase that produces $1,25(\mathrm{OH}) 2-\mathrm{D} 3$ in the kidney $[14,18]$.

\subsection{Vitamin D and IGF-I}

In epiphyseal chondrocytes, $1,25(\mathrm{OH}) 2-\mathrm{D} 3$ potentiates IGF-I synthesis and stimulates cell differentiation and this proliferative effect is mediated by local IGF-I synthesis [19]. In addition, it has been demonstrated that mice knocked out for the vitamin D receptor (VDR) have lower IGF-I levels compared with controls [20].

Soliman et al. measured the circulating 250H-D3 and IGF-I in 46 children with vitamin D deficiency before and 6 months after treatment with one intramuscular injection of vitamin D3 megadose (300,000 IU). At presentation, patients were significantly shorter and had markedly lower growth velocity compared with normal controls. Six months after treatment, height and growth velocity increased significantly in concomitant with a significant increase in $250 H-D 3$ levels. The $250 H-D 3$ concentrations were significantly correlated with the IGF-I levels both before and after treatment, and a significant correlation was found between growth velocity after vitamin D treatment and the increase in IGF-I and 25OH-D3 levels. These data denote that accelerated linear growth after treatment of nutritional vitamin D deficiency is mediated through activation of the
GH/IGF-I system and suggests an important role of vitamin D as a link between the proliferating cartilage cells of the growth plate and $\mathrm{GH} /$ IGF-I secretion [21]. These data have been confirmed by Ameri et al., who prospectively measured IGF-I levels before and after 12 weeks of treatment with oral vitamin D3 (5000 or $7000 \mathrm{IU} /$ week) vs. no intervention in 39 healthy adults. They found that in the 7000 IU group, IGF-I levels significantly increased, while they did not change in controls. In addition, the concentration of $250 \mathrm{H}-\mathrm{D} 3$ was retrospectively assessed in 69 GHD patients on stable hormone replacement. The authors demonstrated higher IGF-I levels in GHD patients with higher $250 \mathrm{H}-\mathrm{D} 3$ levels ( $\geq 15 \mathrm{ng} / \mathrm{ml}$ ), and a logistic regression analysis confirmed a significant positive association between $\geq 15 \mathrm{ng} / \mathrm{ml} 250 \mathrm{H}-\mathrm{D} 3$ levels and higher IGF-I [22]. Confirmatory data in healthy populations were collected by Bogazzi et al., who identified a positive relationship between serum $250 \mathrm{H}-\mathrm{D} 3$ and IGF-I concentrations in 241 healthy subjects [23], and by Hippönen et al. in a large population of 6810 British adult subjects [6], concluding that $250 \mathrm{H}-\mathrm{D} 3$ status may contribute to determining serum IGF-I levels.

\section{GHD and vitamin D}

It is well established that GHD is associated with decreased bone mineral density in children and adults [24], in addition to a series of cardiovascular risk factors. Although GH and IGF-I have direct skeletal and metabolic effects, it is also possible that reduced vitamin D levels may mediate some of the deleterious consequences of GHD. 


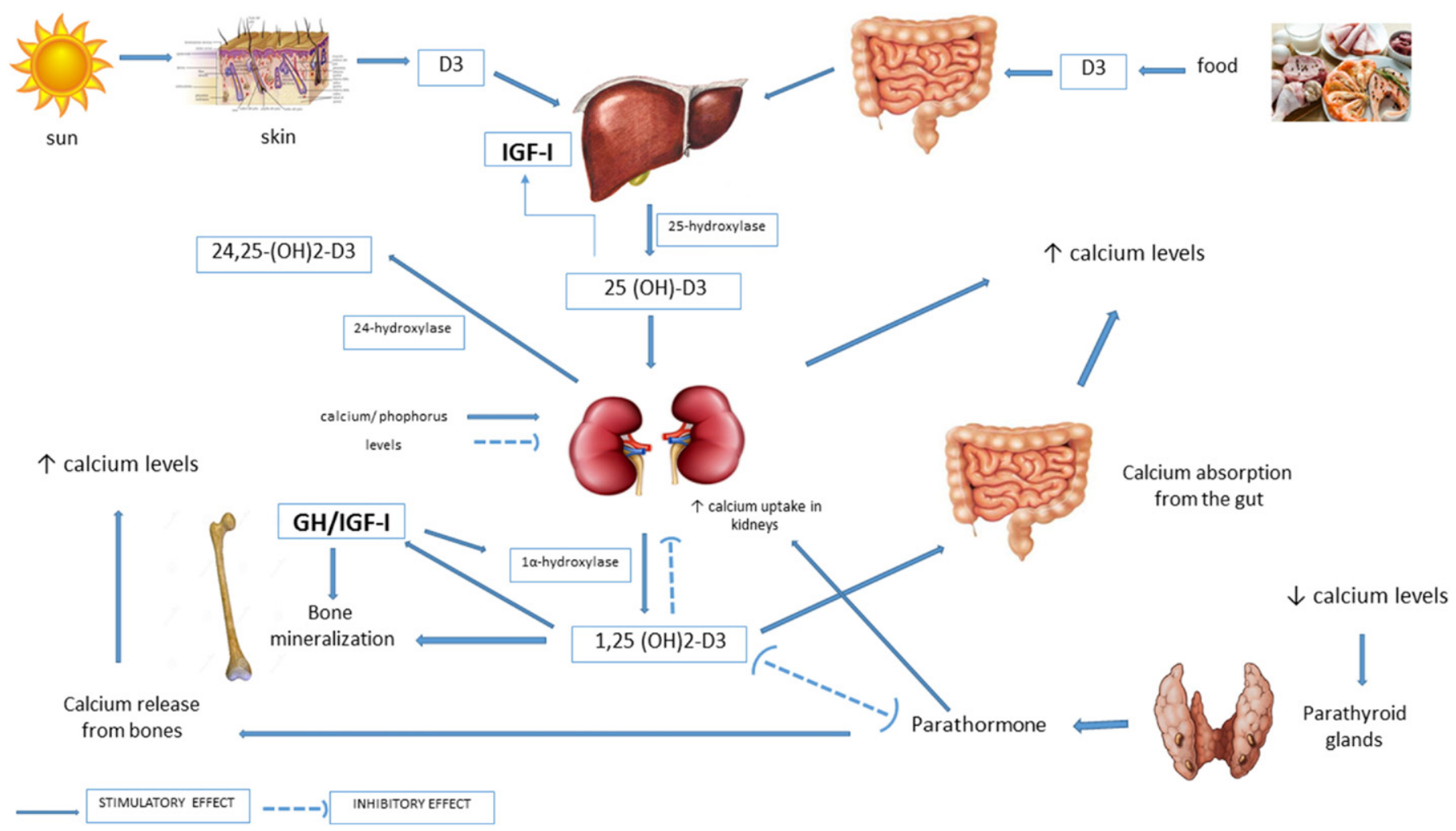

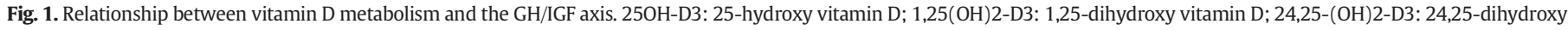
vitamin D.

\subsection{Impact of GHD on vitamin D levels}

Several studies have investigated vitamin D status in patients, both adults and children, with overt GHD, with discordant results.

In 1998 de Boer et al. showed reduced serum 1,25(OH)2-D3 levels in adult patients with childhood-onset multiple pituitary hormone deficiencies (MPHD), while these results have not been confirmed in patients who had isolated GHD, probably as a result of a non-optimal thyroid, gonadal, or adrenal hormone replacement. The ratio of 1,25(OH)2-D3 to $25 \mathrm{OH}-\mathrm{D} 3$ was significantly lower than normal only in patients with MPHD, even when the ratio was adjusted for serum PTH and, overall, 33\% of the MPHD patients had 1,25(OH)2-D3 levels below the 5th percentile. Because of these evidences, the authors did not consider GHD as a condition of vitamin D deficiency [25]. Similar evidences of normal vitamin $D$ levels have been found by other authors in studies performed in both childhood and adult-onset GHD [26-28].

Conversely, reduced 1,25(OH)2-D3 or 25OH-D3 levels in children with GHD have also been demonstrated $[29,30]$. Ciresi et al. found that $40 \%$ of Sicilian children with GHD at baseline had vitamin D deficiency and 35\% had vitamin D insufficiency, respectively [31]. Similarly, Savanelli et al. showed a prevalence of $51 \%$ of vitamin D deficiency and $27 \%$ of vitamin D insufficiency in GHD adult patients [32]. By contrast, Hitz et al. showed a gender difference in vitamin D levels of adult GHD patients at baseline. Indeed, 1,25( $\mathrm{OH}) 2-\mathrm{D} 3$ and the metabolite $25 \mathrm{OH}-\mathrm{D} 3$ of the male subjects were at the same level in patients and healthy controls, while female patients had significantly lower levels of 1,25(OH)2-D3 without any difference in 25OH-D3 levels [33].

\subsection{Impact of $G H$ treatment on vitamin $D$ levels}

Vitamin D sufficiency may be required to obtain optimal effects of $\mathrm{GH}$ treatment on bone quality in GHD patients. In a prospective study conducted in 57 adult GHD patients treated with GH for 2 years, a differential effect of GH treatment on bone mineral density was observed, according to the vitamin D levels. Indeed, the trabecular bone score only increased in the cohort of patients with $250 \mathrm{H}-\mathrm{D} 3$ above the 50th percentile [34].

However, only a few conflicting studies have prospectively analyzed vitamin $\mathrm{D}$ before and after $\mathrm{GH}$ treatment and the reports on the effects of GH treatment on vitamin D and its metabolites vary from a decrease to no change or an increase after treatment.

Chipman et al. in 1980 have hypothesized a relative intestinal resistance to vitamin $\mathrm{D}$ in children with GHD because of the evidence of a decrease in serum 1,25(OH)2-D3 after 5-14 months of GH treatment [35].

By contrast, some studies have shown no significant effect of $\mathrm{GH}$ treatment on vitamin D levels, in both children and adults. Changes in vitamin D metabolites were studied in 9 children with GHD before and during GH treatment by Gertner et al. By comparison with pretreatment values, the GH-treated children showed no significant change in serum concentrations of 25OH-D3, 1,25(OH)2-D3 and 24,25(OH)2-D3. The authors concluded that although $\mathrm{GH}$ has been proposed as a regulator of vitamin D metabolism, the results of this study demonstrate that the changes in bone metabolism accompanying $\mathrm{GH}$ treatment are not mediated via changes in vitamin D status [36]. In 12 GHD children treated for 1 week with high dose (5 IU/day) GH therapy, and again at 1 month, 3 months, and 1 year of replacement therapy $(0.1 \mathrm{IU} / \mathrm{kg}$ to a maximum dose of 2 IU three times weekly), Burstein et al. found that the mean serum 1,25(OH)2-D3 concentration significantly rose on the seventh day of high-dose therapy, returning to pre-therapy values by 1 month. The authors concluded that high dose GH therapy in GHD children markedly raises the 1,25( $\mathrm{OH}) 2$-D3 concentration, but that long-term, physiological replacement therapy does not produce this effect [37].

In 1996 Amato et al. evaluated the effect of 12 months of GH treatment in 9 adult patients with congenital (7 patients) and acquired ( 2 patients) GHD. Serum 25OH-D3 and other markers of bone metabolism were evaluated before, after 12 months of therapy and after 12 months 
off, using a low weekly dose (70 pg/ $\mathrm{kg} /$ week divided into 3 injections). Despite a significant improvement in IGF-I levels and in bone mineral density, no significant changes were found during the study in vitamin $\mathrm{D}$ and in other bone markers, indicating that $\mathrm{GH}$ acts on bone structure and its effects can be direct or mediated by IGF-I and not by vitamin D [28]. However, the low dose used and the frequency of GH administration must be taken into account in the interpretation of these results. Similar results came from the study by Hansen et al., who showed unaltered 1,25( $\mathrm{OH}) 2$-D3 levels in 29 adult patients with GHD treated with GH for 12 months [38]. Similarly, 6 months of GH treatment did not affect the 1,25(OH)2-D3 levels in a small group of GHD adults in the study by Valk et al. [39].

Conversely, several studies found that $\mathrm{GH}$ administration had a stimulatory effect on serum 1,25(OH)2-D3 and the mechanism seems to be the enhanced activity of renal 1 alpha-hydroxylase through IGF-I. This evidence could explain the correlation between the increase in vitamin D, IGF-I and bone mineral density [40]. A few years ago the effect of GH treatment on vitamin D metabolism was evaluated in 26 children with GHD. All children showed a significant increase in serum levels of 1,25( $\mathrm{OH}) 2-\mathrm{D} 3$ after 12 months of GH treatment [29]. The results of the study by Wei et al. performed on 12 GHD children before and after 6 months of GH treatment showed levels of vitamin D metabolites within normal ranges before treatment and confirmed the action of GH in modulating vitamin D metabolism mediated by IGF-I, and not PTH. In that study, the authors demonstrated that $1,25(\mathrm{OH}) 2-\mathrm{D} 3$ levels increased after 1 and 3 months of treatment; 24,25( $\mathrm{OH}) 2-\mathrm{D} 3$ levels were decreased at 1 and 3 months, and then returned to the baseline levels at 6 months, whereas 25OH-D3 levels did not significantly change [27]. A similar stimulatory effect of GH on 1,25( $\mathrm{OH}) 2-\mathrm{D} 3$ levels was demonstrated by Boot et al. in 39 GHD children after 36 months of GH treatment [26]. Ciresi et al. showed a low prevalence of vitamin D sufficiency (25\%) in a cohort of 80 GHD children, with a significant correlation between vitamin $\mathrm{D}$ and the area under the curve of GH calculated during the stimulation test at diagnosis. After 12 months of GH treatment, a significant increase in prevalence of children with vitamin $\mathrm{D}$ sufficiency (50\%) was found. The absence of correlation between vitamin D and IGF-I levels in this study suggested a direct stimulatory effect of GH on vitamin D, not necessarily mediated by the IGF-I increase. This finding was supported by the evidence that children with lower GH values, and not IGF-I, at baseline showed concomitant lower vitamin D levels [31].

Comparable data have been reported in studies performed in adult GHD patients. In 1992 Binnerts et al. demonstrated an increase in 1,25( $\mathrm{OH}) 2-\mathrm{D} 3$ levels, with unchanged 25OH-D3, after 6 months of treatment in 8 adult patients [41]. Conversely, Ahmad et al. investigated the effects of $1,3,6$, and 12 months of GH treatment in 16 adult patients, showing a significant increase in both 1,25(OH)2-D3 and 25OH-D3 levels [42]. In addition, Bianda et al. demonstrated that IGF-I stimulates renal 1 alpha-hydroxylase activity in vivo. In 8 adult GHD patients treated short-term with continuous subcutaneous infusion of IGF-I and with daily subcutaneous injection of GH in a randomized cross-over study, the total 1,25(OH)2-D3 rose significantly although the PTH, calcium, and phosphate levels remained unchanged [43]. Therefore, IGF-I administration, similarly to $\mathrm{GH}$, seems to be able to stimulate bone metabolism and the production of 1,25(OH)2-D3 in GHD adults.

During the last few years, vitamin D deficiency has also emerged as an additional potential cardiovascular risk factor [44-46]. The impact of vitamin D deficiency on cardiovascular risk was explored by Savanelli et al. in 41 hypopituitaric patients with GHD and 41 controls. The authors showed an association between the presence of hypovitaminosis D and the prevalence of dyslipidemia, hypertension and metabolic syndrome and stated that hypovitaminosis D was the most powerful predictor of the prevalence of dyslipidemia and hypertension, suggesting the involvement of vitamin D in the cardiovascular risk in GHD patients [32]. Therefore, its metabolic role in GHD has generated growing interest [47]. It is noteworthy that the interplay between vitamin D and GH/IGF-I system may be even more complex than it appears because of local interactions in vessels. Indeed, the role of vitamin D in the relationship between carotid artery intima-media thickness and IGF-I levels has been hypothesized [48].

\subsection{Summary}

The majority of authors evaluating vitamin D in GHD showed decreased levels in GHD patients, with a gender difference found only in 1 study, while in 4 studies GHD was not considered a condition of vitamin $\mathrm{D}$ deficiency. If vitamin $\mathrm{D}$ sufficiency seems to be required to obtain optimal effects of GH treatment, the impact of GH treatment on vitamin D levels remains controversial. While in just 1 study performed in children vitamin D levels decreased during GH therapy, the majority of studies have shown unchanged or increased vitamin D levels. Specifically, 2 studies performed in children and 3 studies performed in adults showed no effect of GH on vitamin D, while 4 studies in children and 3 studies in adults confirmed a stimulatory effect of GH. Conversely, very few studies have evaluated vitamin D deficiency as a cardiovascular risk factor in GHD.

\section{Acromegaly and vitamin D}

In acromegaly, a condition characterized by chronic GH excess, both increased and decreased vitamin D levels have been highlighted and the interplay between vitamin D and GH/IGF-I axis becomes even more complicated when we consider acromegaly treatment, both medical and surgical.

\subsection{Impact of acromegaly on vitamin D levels}

In 1979 Eskildsen et al. performed one of the first studies on vitamin D metabolism in acromegaly. In 15 acromegalic subjects the authors found elevated plasma levels of both 1,25(OH)2-D3 and 24,25(OH)2D3. Serum PTH being normal in all patients, without measurable changes during the observation period, the high basal vitamin D levels might therefore be explained by a direct effect of GH rather than by increased PTH action. Conversely, 25OH-D3 was low at baseline [49]. The authors postulated that the low serum $250 \mathrm{H}-\mathrm{D} 3$ concentrations found in acromegalic patients might be due to a direct effect on the liver microsomal enzyme system, since it is well known that GH decreases the hepatic microsomal metabolism of a number of drugs [50]. Similar data about increased circulating 1,25(OH)2-D3 concentrations in acromegaly have been found by other authors. For example, in 1980 Brown et al. showed high 1,25(OH)2-D3 levels in 14 acromegalic patients, confirming that $\mathrm{GH}$ is an important regulator of renal vitamin D metabolism [51].

Case reports documented 2 cases of 1,25(OH)2-D3-dependent hypercalcemia associated with $\mathrm{GH}$ excess. In these cases, the complete resection of the pituitary tumor produced biochemical remission of acromegaly and normalization of calcium and 1,25(OH)2-D3levels, while incomplete resection was associated with persistent $1,25(\mathrm{OH}) 2-$ D3-dependent hypercalcemia. In these patients, acromegaly was considered a cause of 1,25(OH)2-D3-dependent hypercalcemia [52].

Regarding the relationship between total vitamin D concentrations and acromegaly, in 1985 Takamoto et al. studied a small group of patients with acromegaly, showing that the mean serum 25OH-D3 levels were significantly lower and the 1,25(OH)2-D3 levels were significantly higher in acromegaly compared with normal subjects. The authors concluded that excessive $\mathrm{GH}$ secretion might stimulate production of 1,25( $(\mathrm{OH}) 2-\mathrm{D} 3$ and might also directly stimulate calcium absorption [53]. Similarly, other studies have confirmed the higher levels of 1,25 $(\mathrm{OH}) 2-\mathrm{D} 3$ in acromegalic patients when compared to normal healthy controls [54]. In addition, Lund et al. demonstrated that acromegalic subjects have elevated serum levels of both 1,25 (OH)2-D3 and 24,25 $(\mathrm{OH}) 2-\mathrm{D} 3$, perhaps as a consequence of a direct action of GH on renal 
1 alpha-hydroxylase activity [55]. Kamenicky et al. compared patients with active and inactive acromegaly and observed similar 25OH-D3 and increased 1,25(OH)2-D3 levels in active acromegaly [56]. The mechanism of the increase in serum 1,25(OH)2-D3 in acromegaly may involve a pathway independent from the PTH-mediated pathway, as documented by a case report presented by Ueda et al., which reported a case of primary hyperparathyroidism associated with acromegaly. Although serum PTH levels increased after resection of the pituitary adenoma, levels of serum 1,25(OH)2-D3 remained above the normal upper limit. In addition, since serum 1,25(OH)2-D3 levels decreased in spite of the increase in serum PTH levels after normalization of GH levels, GH may have contributed to the elevation of serum 1,25(OH)2D3 [57]. In addition, it has been postulated that patients with acromegaly have larger skin areas, which potentially could result in increased 25OH-D3 synthesis and increased 1,25( $\mathrm{OH}) 2-\mathrm{D} 3$ production [58].

Conversely, some studies have not shown any alteration in vitamin D levels in acromegaly. In a study performed on 126 patients with acromegaly, mean vitamin D levels were sufficient at baseline [59]. These data were confirmed by Ho et al., who showed 1,25(OH)2-D3 levels within normal limits in a case series of 25 acromegalic patients [60]. The normal 1,25(OH)2-D3 levels in this group could suggest the mechanism of increased gut sensitivity to $1,25(\mathrm{OH}) 2-\mathrm{D} 3$ in these patients [61].

On the other hand, few studies have shown low vitamin D levels in acromegalic patients. In 55 acromegalic patients, divided into those with active acromegaly (AA), well-controlled acromegaly (WCA) and cured acromegaly (CA), Halupczok-Żyła et al. recorded vitamin D deficiency in all AA patients (100\%), 13 WCA patients (92.86\%), and 10 CA patients (62.5\%), concluding that active acromegalic patients have lower vitamin $\mathrm{D}$ levels in comparison with controls and are at higher risk of vitamin D deficiency. The authors indicated that this result may be related to the higher BMI in the active acromegaly [62]. Similarly, Bonadonna et al. found low total 25OH-D3 levels in postmenopausal women with acromegaly who had vertebral fracture compared to women with acromegaly who had no vertebral fracture [63].

There are no data about free $250 \mathrm{H}-\mathrm{D} 3$ concentrations, which are suggested to be important in the determination of vitamin D deficiency, in acromegaly. Altinova et al. studied 54 patients with acromegaly and 32 control subjects who were similar according to age, gender, and body mass index. In this setting the authors for the first time evaluated free $250 \mathrm{H}-\mathrm{D} 3$ levels, in addition to the vitamin D binding protein (VDBP). Serum VDBP levels were found to be increased in patients with acromegaly compared to control subjects, while there was statistically no significant difference in serum total $250 \mathrm{H}-\mathrm{D} 3$ levels. Conversely, the authors found lower free 250H-D3 levels in patients with acromegaly compared to control subjects. Although the role of excess GH and IGF-I in the regulation of VDBP is not currently known, as a hypothesis, the IGF-I excess in patients with acromegaly may have some effects on VDBP concentrations via paracrine mechanisms since both IGF-I and VDBP are secreted from the liver [64].

In 52 acromegaly patients VDR polymorphism was hypothesized to play a role in the course of acromegaly as a consequence of altering hormonal status. Consequently, the authors stated that vitamin D levels should be considered and followed up in the treatment of acromegaly patients [65].

\subsection{Impact of acromegaly treatment on vitamin $D$ levels}

Acromegaly treatment, both medical and surgical, seems to significantly impact on vitamin D levels in the majority of the studies, although not all studies are in agreement on this.

Medical treatment with bromocriptine for 6 months was found to significantly reduce the plasma levels of both 1,25(OH)2-D3 and 24,25(OH)2-D3. Conversely, 25OH-D3 remained unaffected by the treatment [49]. Similar data were found by Lund et al., who demonstrated a significant decrease in serum concentrations of 1,25 (OH)2-D3 and
24,25 (OH)2-D3 accompanied by a reduction in urinary GH excretion after a period of about 6 months of bromocriptine treatment [55]. The impact of bromocriptine on vitamin $\mathrm{D}$ levels was also evaluated by Bijlsma et al. in 17 acromegalic patients, who responded to either medical treatment with bromocriptine (12 patients) or transsphenoidal surgery (5 patients). Serum 1,25(OH)2-D3 decreased and 24,25( $\mathrm{OH}) 2-\mathrm{D} 3$ increased, without a correlation between the changes in serum $\mathrm{GH}$ levels and 1,25(OH)2-D3, suggesting an indirect effect of growth hormone on renal 1 alpha-hydroxylase [66].

Given that somatostatin analogs (SA) can increase fat in the stools, which can lead to loss of fat-soluble vitamins, the prevalence of fat-soluble vitamin deficiencies in long-term SA users was investigated in 19 acromegalic patients using SA for $\geq 18$ months. Deficiency for $250 H-D 3$ occurred in $21 \%$ of the patients and treatment duration did not influence vitamin levels. The authors concluded that fat-soluble vitamin deficiencies are frequent during long-term SA treatment and that these vitamins, including vitamin $\mathrm{D}$, should be monitored in these patients [67].

Conversely, some studies did not show any alteration in vitamin D levels during medical treatment. In a study performed on 126 patients, $250 H-D 3$ levels were evaluated longitudinally prior to and during short (mean 3 months) and long-term (mean 49 months) SA administration. Mean 25OH-D3 levels did not change during short and long-term SA therapy, suggesting that long-term SA therapy does not affect serum vitamin D [59]. Similar data were found by Cappelli et al., who demonstrated that 24 months of treatment with lanreotide in 35 patients with acromegaly did not associate with significant changes in 1,25(OH)2-D3 levels [68]. Conversely, only during the short-term treatment ( 8 and 14 days) with octreotide, was a rise shown in mean serum $1,25(\mathrm{OH}) 2$ D3, with no changes in VDBP [69]. Ho et al. also evaluated the effect of SA and surgical treatment in 5 and 2 patients respectively, showing that serum 1,25(OH)2-D3 did not change after both treatments [60].

Sixteen patients with acromegaly treated with the growth hormone receptor antagonist, pegvisomant, had a reduction in 1,25(OH)2-D3 levels after normalization of IGF-I, with unaffected 25OH-D3 levels. These data provided further evidence of the effectiveness of pegvisomant in normalizing the altered biological effects of GH hypersecretion [70].

As regards the impact of surgical therapy, Takamoto et al. in 1985 studied a small group of patients with acromegaly before and 3-4 weeks after pituitary adenomectomy. The serum 25OH-D3 levels did not change, while the serum 1,25(OH)2-D3 concentrations fell significantly [53]. Similarly, White et al. demonstrated a reduction in 1,25(OH)2-D3 levels in 10 patients after surgical treatment of acromegaly [54].

\subsection{Summary}

The majority of studies showed increased vitamin D levels in acromegalic patients, confirming that $\mathrm{GH}$ is an important regulator of renal vitamin D metabolism, likely due to a direct action of $\mathrm{GH}$ on renal 1 alpha-hydroxylase activity. Similarly, almost all studies agree in showing a decrease in vitamin D during medical therapy with bromocriptine or pegvisomant and after surgery. Instead, there is some discrepancy as regards the effects of therapy with SA on vitamin D, which is reduced or unchanged after therapy, likely due to the different therapeutic regimens used.

\section{Concluding remarks}

The mutual interplay between vitamin D and the GH/IGF-I system is very complex. Physiologically, GH regulates renal 1 alpha-hydroxylase activity and plasma concentrations of vitamin D and this effect may be IGF-I mediated. On the other hand, vitamin D increases circulating IGF-I.

Commonly, in GHD patients vitamin D levels are almost normal or even lower than in controls, with a variable prevalence of insufficiency or deficiency, and this condition could potentially worsen the already 
known cardiovascular and metabolic risk of GHD patients, although very few studies have evaluated vitamin D deficiency as a cardiovascular risk factor in GHD. On the other hand, the impact of GH treatment on vitamin D levels remains controversial. Although some studies have shown a neutral effect of GH treatment on vitamin D, GH seems to be able to improve vitamin D levels in the majority of the studies available. However, whether GH therapy will improve vitamin D status and consequently also decrease cardiovascular morbidity in GHD patients remains to be determined.

In acromegaly, vitamin D levels are commonly higher than in controls or in patients with controlled disease. Both medical and surgical treatments of acromegaly lead to a reduction in vitamin D levels in the majority of studies, with some exceptions that proves a neutral effect of SA treatment.

To date, the lack of large randomized and placebo-controlled studies, the heterogeneity of the populations evaluated, the relative small study population, the difference in the vitamin D metabolites analyzed in the various studies and the different duration of the various treatments make the literature still quite confusing and sometimes conflicting. Nevertheless, since in the majority of the studies the conditions of $\mathrm{GH}$ deficiency or GH excess seem to be almost always associated with altered vitamin D levels, vitamin D should be considered a useful marker of the integrity of the GH/IGF-I system and should be included among the clinical evaluations to be performed in these conditions. However, whether the vitamin D status in GH disorders and during their respective treatments has a significant clinical impact, for instance in metabolic alterations and cardiovascular morbidity, remains to be determined.

\section{Disclosure statement}

The authors have nothing to disclose.

\section{Grants}

This research did not receive any specific grant from any funding agency in the public, commercial or non-profit sector.

\section{Conflict of interest}

All authors declare that there is no conflict of interest that could be perceived as prejudicing the impartiality of the research reported.

\section{References}

[1] G. Mazziotti, S. Chiavistelli, A. Giustina, Pituitary diseases and bone, Endocrinol. Metab. Clin. N. Am. 44 (1) (2015) 171-180.

[2] M. Doga, S. Bonadonna, M. Gola, G. Mazziotti, A. Giustina, Growth hormone deficiency in the adult, Pituitary 9 (2006) 305-311.

[3] R.D. Murray, J.E. Adams, S.M. Shalet, A densitometric and morphometric analysis of the skeleton in adults with varying degrees of growth hormone deficiency, J. Clin. Endocrinol. Metab. 91 (2) (2006) 432-438.

[4] A. Giustina, G. Mazziotti, E. Canalis, Growth hormone, insulin-like growth factors, and the skeleton, Endocr. Rev. 29 (2008) 535-559.

[5] G. Mazziotti, F. Maffezzoni, S. Frara, A. Giustina, Acromegalic osteopathy, Pituitary, 2016 Oct 5 (Epub ahead of print).

[6] E. Hyppönen, B.J. Boucher, D.J. Berry, C. Power, 25-hydroxyvitamin D, IGF-1, and metabolic syndrome at 45 years of age: a cross-sectional study in the 1958 British Birth Cohort, Diabetes 57 (2) (2008) 298-305.

[7] E.M. Spencer, O. Tobiassen, The mechanism of the action of growth hormone on vitamin D metabolism in the rat, J. Endocrinol. 108 (3) (1981) 1064-1070.

[8] N. Wongsurawat, H.J. Armbrecht, T.V. Zenser, L.R. Forte, B.B. Davis, Effects of hypophysectomy and growth hormone treatment on renal hydroxylation of 25hydroxycholecalciferol in rats, J. Endocrinol. 101 (3) (1984) 333-338.

[9] O. Fontaine, H. Pavlovitch, S. Balsan, 25-hydroxycholecalciferol metabolism in hypophysectomized rats, Endocrinol. 102 (6) (1978) 1822-1826.

[10] G.D. Ogle, A.R. Rosenberg, D. Calligeros, G. Kainer, Effects of growth hormone treatment for short stature on calcium homeostasis, bone mineralisation, and body composition, Horm. Res. 41 (1) (1994) 16-20.

[11] J.M. Quesada, W. Coopmans, B. Ruiz, P. Aljama, I. Jans, R. Bouillon, Influence of vitamin D on parathyroid function in the elderly, J. Clin. Endocrinol. Metab. 75 (1992) 494-501.
[12] R. Marcus, G. Butterfield, L. Holloway, L. Gilliland, D.J. Baylink, R.L. Hintz, B.M. Sherman, Effects of short-term administration of recombinant human growth hormone to elderly people, J. Clin. Endocrinol. Metab. 70 (1990) 519-527.

[13] K. Brixen, H.K. Nielsen, R. Bouillon, A. Flyvbjerg, L. Mosekilde, Effects of short-term growth hormone treatment on PTH, calcitriol, thyroid hormones, insulin and glucagon, Acta Endocrinol. 127 (1992) 331-336.

[14] T. Bianda, M.A. Hussain, Y. Glatz, R. Bouillon, E.R. Froesch, C. Schmid, Effects of shortterm insulin-like growth factor-i or growth hormone treatment on bone turnover, renal phosphate reabsorption and 1,25 dihydroxyvitamin $\mathrm{d} 3$ production in healthy man, J. Intern. Med. 241 (2) (1997) 143-150.

[15] L. Condamine, F. Vztovsnik, G. Friedlander, C. Menaa, M. Garabedian, Local action of phosphate depletion and insulin-like growth factor-I on in vitro production of 1,25dihydroxyvitamin D3 by cultured mammalian kidney cells, J. Clin. Invest. 94 (1994) 1673-1679.

[16] N.M. Wright, N. Papadea, B. Wentz, B. Hollis, S. Willi, N.H. Bell, Increased serum 1,25 dihydroxyvitamin $\mathrm{D}$ after growth hormone administration is not parathyroid hormone-mediated, Calcif. Tissue Int. 61 (1997) 101-103.

[17] J.M. Gómez, F.J. Maravall, N. Gómez, M.A. Navarro, R. Casamitjana, J. Soler, Relationship between 25-(OH) D3, the IGF-I system, leptin, anthropometric and body composition variables in a healthy, randomly selected population, Horm. Metab. Res. 36 (1) (2004) 48-53.

[18] S. Wei, H. Tanaka, Y. Seino, Local action of exogenous growth hormone and insulinlike growth factor-I on dihydroxyvitamin D production in LLC-PK1 cells, Eur. J. Endocrinol. 139 (1998) 454-460.

[19] H. Robson, T. Siebler, S.M. Shalet, G. Williams, Interactions between GH, IGF-I, glucocorticoids, and thyroid hormones during skeletal growth, Pediatr. Res. 52 (2002) 137-147.

[20] Y. Song, S. Kato, J.C. Fleet, Vitamin D receptor (VDR) knockout mice reveal VDR-independent regulation of intestinal calcium absorption and $\mathrm{ECaC} 2$ and calbindin D9k mRNA, J. Nutr. 133 (2003) 374-380.

[21] A.T. Soliman, F. Al Khalaf, N. Alhemaidi, M. Al Ali, M. Al Zyoud, K. Yakoot, Linear growth in relation to the circulating concentrations of insulin-like growth factor I, parathyroid hormone, and 25-hydroxy vitamin $\mathrm{D}$ in children with nutritional rickets before and after treatment: endocrine adaptation to vitamin D deficiency, Metabolism 57 (1) (2008) 95-102.

[22] P. Ameri, A. Giusti, M. Boschetti, M. Bovio, C. Teti, G. Leoncini, D. Ferone, G. Murialdo, F. Minuto, Vitamin D increases circulating IGF1 in adults: potential implication for the treatment of GH deficiency, Eur. J. Endocrinol. 169 (6) (2013) 767-772.

[23] F. Bogazzi, G. Rossi, M. Lombardi, L. Tomisti, C. Sardella, L. Manetti, O. Curzio, C. Marcocci, L. Grasso, M. Gasperi, E. Martino, Vitamin D status may contribute to serum insulin-like growth factor I concentrations in healthy subjects, J. Endocrinol. Investig. 34 (8) (2011) e200-e203.

[24] N.A. Tritos, B.M. Biller, Growth hormone and bone, Curr. Opin. Endocrinol. Diabetes Obes. 16 (6) (2009) 415-422.

[25] H. de Boer, G.J. Blok, C. Popp-Snijders, A. Sips, P. Lips, E. van der Veen, Intestinal calcium absorption and bone metabolism in young adult men with childhood-onset growth hormone deficiency, J. Bone Miner. Res. 13 (2) (1998) 245-252.

[26] A.M. Boot, M.A. Engels, G.J. Boerma, E.P. Krenning, S.M. De Muinck Keizer-Schrama, Changes in bone mineral density, body composition, and lipid metabolism during growth hormone $(\mathrm{GH})$ treatment in children with $\mathrm{GH}$ deficiency, J. Clin. Endocrinol. Metab. 82 (8) (1997) 2423-2428.

[27] S. Wei, H. Tanaka, T. Kubo, T. Ono, S. Kanzaki, Y. Seino, Growth hormone increases serum 1,25-dihydroxyvitamin D levels and decreases 24,25-dihydroxyvitamin D levels in children with growth hormone deficiency, Eur. J. Endocrinol. 136 (1) (1997) 45-51.

[28] G. Amato, G. Izzo, G. La Montagna, A. Bellastella, Low dose recombinant human growth hormone normalizes bone metabolism and cortical bone density and improves trabecular bone density in growth hormone deficient adults without causing adverse effects, Clin. Endocrinol. 45 (1) (1996) 27-32.

[29] G. Saggese, G.I. Baroncelli, S. Bertelloni, L. Cinquanta, G. Di Nero, Effects of long-term treatment with growth hormone on bone and mineral metabolism in children with growth hormone deficiency, J. Pediatr. 122 (1) (1993) 37-45.

[30] E. Witkowska-Sędek, A. Kucharska, M. Rumińska, B. Pyrżak, Relationship between 25(OH)D and IGF-I in children and adolescents with growth hormone deficiency, Adv. Exp. Med. Biol. 912 (2016) 43-49.

[31] A. Ciresi, F. Cicciò, C. Giordano, High prevalence of hypovitaminosis D in Sicilian children affected by growth hormone deficiency and its improvement after 12 months of replacement treatment, J. Endocrinol. Investig. 37 (7) (2014) 631-638.

[32] M.C. Savanelli, E. Scarano, G. Muscogiuri, L. Barrea, L. Vuolo, M. Rubino, S. Savastano, A. Colao, C. Di Somma, Cardiovascular risk in adult hypopituitaric patients with growth hormone deficiency: is there a role for vitamin D? Endocrine 52 (1) (2016) 111-119.

[33] M.F. Hitz, J.E. Jensen, P.C. Eskildsen, Bone mineral density in patients with growth hormone deficiency: does a gender difference exist? Clin. Endocrinol. 65 (6) (2006) 783-791.

[34] M. Kužma, N. Binkley, A. Bednárová, Z. Killinger, P. Vaňuga, J. Payer, Trabecular bone score change differs with regard to $25(\mathrm{OH}) \mathrm{D}$ levels in patients treated for adultonset growth hormone deficiency, Endocr. Pract. 22 (8) (2016) 951-958.

[35] J.J. Chipman, J. Zerwekh, M. Nicar, J. Marks, C.Y. Pak, Effect of growth hormone administration: reciprocal changes in serum 1 alpha,25-dihydroxyvitamin D and intestinal calcium absorption, J. Clin. Endocrinol. Metab. 51 (2) (1980) 321-324.

[36] J.M. Gertner, R.L. Horst, A.E. Broadus, H. Rasmussen, M. Genel, Parathyroid function and vitamin D metabolism during human growth hormone replacement, J. Clin. Endocrinol. Metab. 49 (2) (1979) 185-188.

[37] S. Burstein, I.W. Chen, R.C. Tsang, Effects of growth hormone replacement therapy on 1,25-dihydroxyvitamin D and calcium metabolism, J. Clin. Endocrinol. Metab. 56 (6) (1983) 1246-1251. 
[38] T.B. Hansen, K. Brixen, N. Vahl, J.O. Jørgensen, J.S. Christiansen, L. Mosekilde, C. Hagen, Effects of 12 months of growth hormone $(\mathrm{GH})$ treatment on calciotropic hormones, calcium homeostasis, and bone metabolism in adults with acquired $\mathrm{GH}$ deficiency: a double blind, randomized, placebo-controlled study, J. Clin. Endocrinol. Metab. 81 (9) (1996) 3352-3359.

[39] N.K. Valk, R.J. Erdtsieck, D. Algra, S.W. Lamberts, H.A. Pols, Combined treatment of growth hormone and the bisphosphonate pamidronate, versus treatment with $\mathrm{GH}$ alone, in GH-deficient adults: the effects on renal phosphate handling, bone turnover and bone mineral mass, Clin. Endocrinol. 43 (3) (1995) 317-324.

[40] M.D. Harbison, J.M. Gertner, Permissive action of growth hormone on the renal response to dietary phosphorus deprivation, J. Clin. Endocrinol. Metab. 70 (1990) 1035-1040.

[41] A. Binnerts, G.R. Swart, J.H. Wilson, N. Hoogerbrugge, H.A. Pols, J.C. Birkenhager, S.W. Lamberts, The effect of GH administration in GH deficient adults on bone, protein, carbohydrate and lipid homeostasis, as well as on body composition, Clin. Endocrinol. 37 (1992) 79-87.

[42] A.M. Ahmad, J. Thomas, A. Clewes, M.T. Hopkins, R. Guzder, H. Ibrahim, B.H. Durham, J.P. Vora, W.D. Fraser, Effects of growth hormone replacement on parathyroid hormone sensitivity and bone mineral metabolism, J. Clin. Endocrinol. Metab. 88 (6) (2003) 2860-2868.

[43] T. Bianda, Y. Glatz, R. Bouillon, E.R. Froesch, C. Schmid, Effects of short-term insulinlike growth factor-I (IGF-I) or growth hormone $(\mathrm{GH})$ treatment on bone metabolism and on production of 1,25-dihydroxycholecalciferol in GH-deficient adults, J. Clin. Endocrinol. Metab. 83 (1) (1998) 81-87.

[44] P. Pludowski, M.F. Holick, S. Pilz, C.L. Wagner, B.W. Hollis, W.B. Grant, Y. Shoenfeld, E. Lerchbaum, D.J. Llewellyn, K. Kienreich, M. Soni, Vitamin D effects on musculoskeletal health, immunity, autoimmunity, cardiovascular disease, cancer, fertility, pregnancy, dementia and mortality-a review of recent evidence, Autoimmun. Rev. 12 (10) (2013) 976-989.

[45] R. Bouillon, L. Verlinden, Does a better vitamin D status help to reduce cardiovascular risks and events? Endocrine 47 (3) (2014) 662-663.

[46] T. Skaaby, L.L. Husemoen, C. Pisinger, T. Jørgensen, B.H. Thuesen, M. Fenger, A. Linneberg, Vitamin D status and incident cardiovascular disease and all-cause mortality: a general population study, Endocrine 43 (3) (2013) 618-625.

[47] J. Isgaard, Cardiovascular risk factors in growth hormone deficiency: is vitamin D a new kid on the block? Endocrine 52 (2016) 3-4.

[48] P. Ameri, M. Canepa, P. Fabbi, G. Leoncini, Y. Milaneschi, M. Mussap, M. AlGhatrif, M. Balbi, F. Viazzi, G. Murialdo, R. Pontremoli, C. Brunelli, L. Ferrucci, Vitamin D modulates the association of circulating insulin-like growth factor- 1 with carotid artery intima-media thickness, Atherosclerosis 236 (2) (2014) 418-425.

[49] P.C. Eskildsen, B. Lund, O.H. Sørensen, B. Lund, J.E. Bishop, A.W. Norman, Acromegaly and vitamin D metabolism: effect of bromocriptine treatment, J. Clin. Endocrinol. Metab. 49 (3) (1979) 484-486.

[50] J.T. Wilson, T.C. Spelsberg, Growth hormone and drug metabolism. Acute effects on microsomal mixed-function oxidase activities in rat liver, Biochem. J. 154 (2) (1976) 433-438.

[51] D.J. Brown, E. Spanos, I. MacIntyre, Role of pituitary hormones in regulating renal vitamin D metabolism in man, Br. Med. J. 280 (6210) (1980) 277-278.

[52] R. Shah, A. Licata, N.M. Oyesiku, A.G. Ioachimescu, Acromegaly as a cause of 1,25dihydroxyvitamin D-dependent hypercalcemia: case reports and review of the literature, Pituitary 15 (Suppl 1) (2012) S17-S22.

[53] S. Takamoto, H. Tsuchiya, T. Onishi, S. Morimoto, S. Imanaka, S. Mori, Y. Seino, T. Uozumi, Y. Kumahara, Changes in calcium homeostasis in acromegaly treated by pituitary adenomectomy, J. Clin. Endocrinol. Metab. 61 (7) (1985) 7-11.
[54] H.D. White, A.M. Ahmad, B.H. Durham, S. Chandran, A. Patwala, W.D. Fraser, J.P. Vora, Effect of active acromegaly and its treatment on parathyroid circadian rhythmicity and parathyroid target-organ sensitivity, J. Clin. Endocrinol. Metab. 91 (3) (2006) 913-919.

[55] B. Lund, P.C. Eskildsen, B. Lund, A.W. Norman, O.H. Sørensen, Calcium and vitamin D metabolism in acromegaly, Acta Endocrinol. 96 (4) (1981) 444-450.

[56] P. Kamenicky, A. Blanchard, C. Gauci, S. Salenave, A. Letierce, M. Lombes, S. BraillyTabard, M. Azizi, D. Prie, J.C. Souberbielle, P. Chanson, Pathophysiology of renal calcium handling in acromegaly: what lies behind hypercalciuria? J. Clin. Endocrinol. Metab. 97 (2012) 2124-2133.

[57] M. Ueda, M. Inaba, H. Tahara, Y. Imanishi, H. Goto, Y. Nishizawa, Hypercalcemia in a patient with primary hyperparathyroidism and acromegaly: distinct roles of growth hormone and parathyroid hormone in the development of hypercalcemia, Intern. Med. 44 (4) (2005) 307-310.

[58] A. Ben-Shlomo, S. Melmed, Skin manifestations in acromegaly, Clin. Dermatol. 24 (4) (2006) 256-259.

[59] A. Ajmal, A. Haghshenas, S. Attarian, M. Barake, N.A. Tritos, A. Klibanski, K.K. Miller, L.B. Nachtigall, The effect of somatostatin analogs on vitamin D and calcium concentrations in patients with acromegaly, Pituitary 17 (4) (2014) 366-373.

[60] P.J. Ho, L.M. Fig, A.L. Barkan, B. Shapiro, Bone mineral density of the axial skeleton in acromegaly, J. Nucl. Med. 33 (9) (1992) 1608-1612.

[61] G. Sigurdsson, V. Nunziata, M. Rainer, A. Nadarajah, O.F. Joplin, Calcium absorption and excretion in the gut in acromegaly, Clin Endocrino 2 (1973) 187-192 (Oxf).

[62] J. Halupczok-Żyła, A. Jawiarczyk-Przybyłowska, M. Bolanowski, Patients with active acromegaly are at high risk of 25(OH)D deficiency, Front. Endocrinol. 6 (2015) 89 (Lausanne).

[63] S. Bonadonna, G. Mazziotti, M. Nuzzo, A. Bianchi, A. Fusco, L. De Marinis, A. Giustina Increased prevalence of radiological spinal deformities in active acromegaly: a cross-sectional study in postmenopausal women, J. Bone Miner. Res. 20 (2005) 1837-1844.

[64] A.E. Altinova, C. Ozkan, M. Akturk, O. Gulbahar, M. Yalcin, N. Cakir, F.B. Toruner, Vitamin D-binding protein and free vitamin D concentrations in acromegaly, Endocrine 52 (2) (2016) 374-379.

[65] M. Ilhan, B. Toptas-Hekimoglu, I. Yaylim, S. Turgut, S. Turan, O. Karaman, E. Tasan, Investigation of the vitamin D receptor polymorphisms in acromegaly patients, Biomed. Res. Int. 2015 (2015) 625981.

[66] J.W. Bijlsma, J.W. Nortier, S.A. Duursma, R.J. Croughs, R. Bosch, J.H. Thijssen, Changes in bone metabolism during treatment of acromegaly, Acta Endocrinol. 104 (1983) 153-159.

[67] H.B. Fiebrich, G. Van Den Berg, I.P. Kema, T.P. Links, J.H. Kleibeuker, A.P. Van Beek, A.M. Walenkamp, W.J. Sluiter, E.G. De Vries, Deficiencies in fat-soluble vitamins in long-term users of somatostatin analogue, Aliment. Pharmacol. Ther. $32(11-12)$ (2010) 1398-1404

[68] C. Cappelli, E. Gandossi, B. Agosti, B. Cerudelli, D. Cumetti, M. Castellano, I. Pirola, E. De Martino, E.A. Rosei, Long-term treatment of acromegaly with lanreotide: evidence of increased serum parathormone concentration, Endocr. J. 51 (6) (2004) 517-520.

[69] L. Fredstorp, Y. Pernow, S. Werner, The short and long-term effects of octreotide on calcium homeostasis in patients with acromegaly, Clin. Endocrinol. 39 (3) (1993) 331-336.

[70] C. Parkinson, M. Kassem, L. Heickendorff, A. Flyvbjerg, P.J. Trainer, Pegvisomant-induced serum insulin-like growth factor-I normalization in patients with acromegaly returns elevated markers of bone turnover to normal, J. Clin. Endocrinol. Metab. 88 (12) (2003) 5650-5655. 